\title{
Política de municipalização: avaliação do desempenho escolar
}

\section{Política de municipalización: evaluación del desempeño escolar Municipalization policy: evaluation of school performance}

THAÍS CONTE VARGAS

Orcid Id: http://orcid.org/0000-0001-8127-5257 Universidade Estadual Paulista

JOSÉ LUÍS BIZELLI

Orcid Id: http://orcid.org/0000-0002-6634-1444

Universidade Estadual Paulista

JOSÉ ANDERSON SANTOS CRUZ

Orcid Id: http://orcid.org/0000-0001-5223-8078

Universidade Estadual Paulista

\begin{abstract}
Resumo: O texto compara o desempenho no Índice de Desenvolvimento da Educação Básica (IDEB) de escolas públicas estaduais e municipais em um município de porte médio do interior paulista. Verifica-se assimetria entre os resultados dos estabelecimentos de ensino sob gestão municipal e aqueles administrados pelo estado, notadamente superiores. De dados obtidos em fontes oficiais e do aprofundamento na literatura pertinente investigou-se o desenho geral do modelo de municipalização proposto e sua implantação na localidade estudada. O estudo conclui que as políticas educacionais formuladas e implementadas pelo município resultam, efetivamente, em menores índices de sucesso educacional, ainda que partam de melhores condições: maior volume de verbas para a execução de seus programas e maior estabilidade do corpo docente.
\end{abstract}

Palavras-chave: Ensino Fundamental. Financiamento da Educação. IDEB. FUNDEB.

Abstract: This paper compares the performance in the Basic Education Development Index (IDEB) of the state and municipal public schools in a medium-sized city in the countryside of São Paulo. An asymmetry is verified between the results of schools under municipal management and those administered by the state, notably higher. From data obtained from official sources and deepening of the pertinent literature, it was investigated the general design of the proposed municipalization model and its implementation in the studied location. The study concludes that the educational policies formulated and implemented by the municipality effectively result in lower rates of educational success, even if they start from better conditions: greater volume of funds for the execution of its programs and greater stability of the teaching faculty.

Keywords: Elementary school. Education Funding. IDEB. FUNDEB. 
Resumen: El texto compara el desempeño en el Índice de Desarrollo de la Educación Básica (IDEB) de escuelas públicas estatales y municipales en una ciudad mediana en el interior de São Paulo. Se verifica asimetría entre los resultados de los establecimientos de enseñanza bajo gestión municipal y los administrados por el estado, notablemente superiores. A partir de los datos obtenidos en fuentes oficiales y en la literatura pertinente se investigó el diseño general del modelo de municipalización propuesto y su implementación en el lugar estudiado. El estudio concluye que las políticas educacionales formuladas e implementadas por el municipio resultan, efectivamente, en menores indices de éxito educacional, aunque partan de mejores condiciones: mayor presupuesto para la ejecución de sus programas y mayor estabilidad de los docentes.

Palabras clave: Enseñanza Primaria. Financiamiento de la Educación. IDEB. FUNDEB.

\section{INTRODUÇÃO}

A partir da Constituição de 1988 (BRASIL, 1988), o Brasil optou por implantar um modelo de municipalização para as políticas públicas governamentais, reorganizando as estratégias do financiamento que dimensionavam a oferta da Educação Fundamental. Entender o desenho geral do modelo proposto e sua implantação em uma localidade específica é o objetivo geral deste trabalho. O campo de análise está circunscrito às escolas públicas de um município médio ${ }^{1}$ do interior do estado de São Paulo e o indicador de desempenho utilizado é o Índice de Desenvolvimento da Educação Básica (IDEB), tomado através de série histórica que se encerra em 2018 e contrastado com outros indicadores disponíveis, como a taxa de distorção idade-série e o índice de esforço docente, por exemplo. Interessa saber como se articula a oferta educativa urbana para o Ensino Fundamental I, dividida entre escolas estaduais e municipais.

A investigação utilizou-se de diferentes métodos e técnicas de pesquisa. Primeiramente, concentrou esforços em estudo bibliográfico sobre a questão da municipalização, compreendendo sua trajetória histórica no país. Nesse exame foram abordados aspectos relacionados à qualidade e ao modelo de financiamento educacional brasileiro. A bibliografia da área e os documentos oficiais - publicações, avaliações e Censo Escolar - disponibilizados pelo INEP forneceram informações sobre as escolas municipais e estaduais do município escolhido.

No Brasil, como já foi dito, a municipalização do Ensino Fundamental (EF) se deu no bojo da redemocratização do país, após a promulgação da Constituição Federal de 1988. Como resposta a demandas oriundas da sociedade civil e política

1 Segundo o IBGE, municípios de médio porte possuem população compreendida entre 100 e 500 mil habitantes. 
no que se refere à maior participação popular na definição das políticas sociais, optou-se por descentralizar a oferta de serviços de saúde, assistência social e educação, transformando os municípios em centros estratégicos de gestão local.

O argumento decisivo para a realocação das responsabilidades governativas residia na proximidade entre o processo de formulação e de execução de políticas públicas: o administrador municipal, estando mais perto das pressões populares, encontrar-se-ia mais preparado para canalizar os desejos e as expectativas daquela localidade, resultando em oferta de serviços locais mais satisfatória. Até então, as políticas públicas brasileiras eram formuladas e implementadas diretamente por agências ligadas ao governo federal e/ou estadual. De acordo com Thiesen (2019, p. 425), "no Brasil, o fim dos anos 1980 marca um tempo de abertura política e com ele a expectativa de maior participação coletiva na gestão das instituições públicas".

O próprio mecanismo da municipalização não foi aceito unanimemente pelos gestores locais, que questionaram a efetivação do volume de repasse transferido para fazer frente ao processo de descentralização de competências (TAVEIRA, 2009). Com a implantação do Fundo de Manutenção e Desenvolvimento do Ensino Fundamental e de Valorização do Magistério $^{2}$ (FUNDEF), os municípios passaram a receber receitas de acordo com as matrículas no EF que detinham. Se o estado permanecesse responsável pela demanda do ensino fundamental, o município não faria jus à parcela do financiamento federal. Essa foi, por exemplo, a opção que tomou Campinas, no estado de São Paulo ${ }^{3}$.

Nacionalmente, a descentralização tem sido apoiada tanto por setores ditos conservadores, quanto progressistas. O manifesto dos Pioneiros da Educação Nova, publicado em 1932 e assinado por intelectuais da área, como Fernando de Azevedo e Anísio Teixeira, propunha a descentralização e autonomia das escolas.

Como resultado desses esforços históricos, o Fundo de Manutenção e Desenvolvimento da Educação Básica e de Valorização dos Profissionais da Educação (FUNDEB) - que passou a vigorar em substituição ao FUNDEF$^{4}$, em 2007 - ampliou a distribuição de recursos financeiros e os ciclos de ensino contemplados. Enquanto o FUNDEF era composto por 15\% das receitas

2 O Fundo de Manutenção e Desenvolvimento do Ensino Fundamental e de Valorização do Magistério foi criado com o objetivo de irrigar com os recursos disponíveis tanto estados quanto municípios brasileiros, para que estes atendessem o novo papel de executor de políticas. É preciso lembrar que ambos os entes federados, em sua grande maioria, eram incapazes de custear a própria rede de ensino, visto que totalmente dependentes de transferências federais.

3 Por municipalização se considera que as escolas de gestão estadual passem à responsabilidade dos municípios, que ampliam suas redes educacionais. No caso de Campinas, a rede municipal permaneceu a mesma, já que o município optou por não assumir escolas estaduais; portanto, passou a receber de acordo com o número de matrículas de sua rede.

O FUNDEF esteve em vigência durante os anos que vão de 1998 a 2006. 
arrecadadas de determinados impostos por estados, Distrito Federal e municípios, além da complementação da União, no caso de fundos estaduais que não atingissem o valor mínimo definido nacionalmente, o FUNDEB passou a contar com $20 \%$ da arrecadação proveniente das mesmas fontes, além da participação da União, em vigor de 2007 a $2020^{5}$.

A destinação também deixou de ser feita com base no número de matrículas no EF: os municípios tiveram incluída a Educação Infantil (EI) e os estados passaram a contar com verba para o Ensino Médio (EM). Todo o sistema, porém, manteve a lógica de gasto per capita, anualmente calculado pelo governo federal, com o objetivo de assegurar, com o valor repassado, um gasto mínimo por cada aluno em todas as localidades do país.

Esse valor mínimo, até hoje, não leva em consideração o cálculo do quanto uma escola necessita, financeiramente, para funcionar segundo um padrão de qualidade determinado pelo governo: tem como base a estimativa de arrecadação de receitas que compõem o fundo. Assim, os recursos disponíveis para a Educação brasileira dependem da disponibilidade orçamentária anual e não de um compromisso com a qualidade definido a priori.

Ao se pensar o momento crítico pelo qual o país atravessa atualmente, com profunda diminuição de arrecadação, os valores repassados aos governos locais também diminuem drasticamente, o que compromete a execução de projetos de longo prazo, além da própria manutenção dos gastos correntes. A complementação da União, de apenas $10 \%$ do valor total arrecadado por todas as demais esferas administrativas, também flutua de acordo com o nível de atividade econômica - visto que o imposto mais expressivo na composição do FUNDEB é o ICMS, que diminui em períodos de recessão econômica.

\section{MUNICIPALIZAÇÃO: UMA TRAJETÓRIA HISTÓRICA}

Conforme definido, a pesquisa teve como campo um município médio do interior paulista, onde foi possível avaliar a associação positiva entre os gastos em Educação e o desempenho no Índice de Desenvolvimento da Educação Básica (IDEB) dos alunos no EF. O município tomado por esta análise é apontado como um caso destoante, onde tal relação não se verifica:

5 É importante salientar que o novo FUNDEB foi aprovado este ano (2020) e altera a parcela de complementação da União e as alíquotas de distribuição aos municípios, além de ser permanente. 
Na região Central [...] podemos observar que os municípios que gastam mais, também estão com os IDEBs maiores, dado que confirma a forte correlação entre IDEB e gasto por aluno-ano/PIB per capita. O município de [...] apresenta um IDEB que não condiz com a média dos gastos realizados, pois seu IDEB é de 5,7, gastos de $\mathrm{R} \$$ 9.762,00 e um PIB per capita de $\mathrm{R} \$ 25.642,00$. (OLIVEIRA, 2015, p. 69, grifo nosso).

Uma das possíveis explicações para o efeito reduzido do aumento de recursos na qualidade do ensino pode residir no modelo brasileiro de transferência escolhido para ser aplicado, que condiciona gastos a rubricas específicas. Ao dispor que 60\% dos recursos do FUNDEB devem ser investidos na remuneração e valorização dos profissionais do magistério, a autonomia dos gestores locais, tão aventada como justificativa da municipalização, é reduzida. O aumento desse gasto, ao longo dos anos, também tem tornado o FUNDEB uma provisão quase que exclusivamente destinada aos gastos com folha de pagamento.

No município escolhido, essa porcentagem foi de 70\% em 2012 para $90 \%$ em 2016 (SIOPE, 2018). De 2008 a 2011, anos para os quais os dados também estão disponíveis, a porcentagem se manteve estável, ao redor de $69 \%$. No estado de São Paulo, para o período de 2011 a 2017, o gasto com pessoal docente esteve na faixa de $65 \%$, o que possibilitou ao estado maior margem financeira para a realização de investimentos.

Martins (2002), ao analisar o processo de municipalização ocorrido no estado de São Paulo no período de 1996 a 2001, primeira fase do esforço de implantação do modelo, constatou que a participação dos municípios nas matrículas de $1^{\mathrm{a}}$ a $4^{\mathrm{a}}$ série foi de $12 \%$ para $44 \%$. No que se refere às matrículas das séries que incluem o 50 e o 80 ano, no entanto, os municípios passaram a ofertar $15 \%$ das matrículas, sendo que ofereciam $10 \%$ no início do período.

A localidade escolhida seguiu a tendência de municipalizar, inicialmente e em maior escala, o primeiro ciclo do EF. O processo de municipalização teve início legal no ano de 1998, a partir de lei promulgada no final de 1997 (Lei n. 4938/1997). Nela, ficou estabelecida a instituição do Sistema Municipal de ensino, que devia abranger a EI e os anos iniciais do EF $-1^{a}$ a $4^{a}$ série, na ocasião -, além de garantir o atendimento de alunos com necessidades especiais, o funcionamento dos centros de educação complementar e a educação supletiva: Educação de Jovens e Adultos (EJA).

A Secretaria Municipal de Educação ofertava então apenas a etapa inicial da Educação Básica (EB), a EI, contando com creches e pré-escolas geridas localmente. Já em 1998, três escolas estaduais passaram para a responsabilidade do município, através de convênio com a Secretaria de Estado de Educação do estado de São Paulo. Nos anos que se seguiram, outras três instituições de ensino 
estaduais foram assumidas pela gestão municipal. Além dessas, outras oito escolas foram construídas pelo município através de recursos repassados via FUNDEF/ FUNDEB, além de dois Centros de Atenção Integral à Criança e ao Adolescente (CAICs), financiados com recursos federais. Atualmente, nove dessas escolas também oferecem os anos finais do EF. A rede estadual é composta por onze escolas de ensino fundamental, ou seja, ambos - município e estado - contam com a mesma quantidade de estabelecimentos de ensino ${ }^{6}$.

Efetivamente, é possível constatar que a verba disponível para as escolas municipais, por aluno, ao menos a partir de 2008, foi maior que os recursos repassados, por aluno, às escolas sob responsabilidade estadual. Através do Sistema de Informações sobre Orçamentos Públicos em Educação (SIOPE), criado pelo Fundo Nacional de Desenvolvimento da Educação, em 2006, é possível comparar informações constantes do orçamento educacional dos estados, Distrito Federal e municípios. Os dados estão desagregados pelos níveis: EI, EF, EM e EJA.

Com os dados disponíveis na plataforma, torna-se possível identificar quanto cada aluno, matriculado no EF - anos iniciais e finais - da rede estadual, recebeu anualmente durante o período compreendido entre 2008 e 2016, conforme pode ser verificado no gráfico abaixo. Também fica patente que, estabelecendose uma comparação, o município sob investigação investiu, no mesmo período, através de transferências recebidas e recursos próprios, verba sempre superior para a manutenção de sua rede.

\section{Gráfico 1 - Dados sobre Investimento educacional por aluno do Ensino Fundamental}

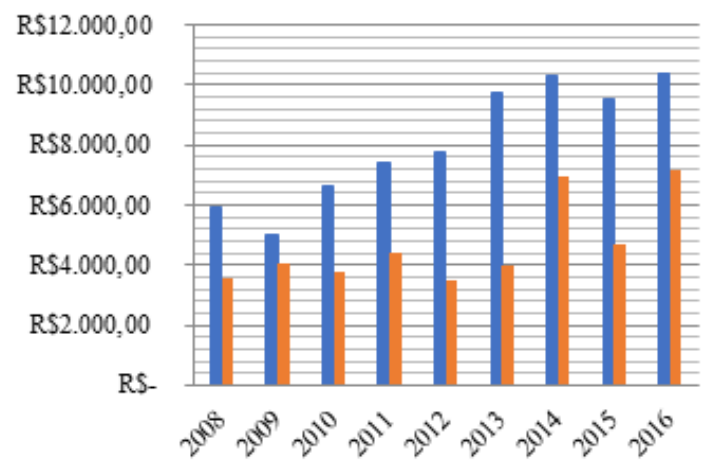

- Investimento educacional por aluno do Ensino Fundamental no município investigado

- Invest imento educacional por aluno do Ensino Fundamental no estado de São Paulo

Fonte: SIOPE (2018) - Elaborado pelos autores

6 Cabe ainda destacar que duas escolas municipais localizadas em assentamentos rurais não serão objeto de análise, pela baixa quantidade de matrículas que ofertam. 
A conclusão lógica de tal análise de gastos levaria à ideia de que o município escolhido como campo de análise possui um sistema de ensino mais bem estruturado, com melhores projetos devido ao maior financiamento, portanto, com melhor desempenho de seus alunos. No entanto, nem sempre maiores despesas resultam em políticas estratégicas mais efetivas. Para investigar o caso em questão, o trabalho vai utilizar-se do IDEB como fator para medir o desempenho dos alunos.

Criado em 2007, o IDEB reúne, em um só indicador, os resultados de dois conceitos considerados pela literatura da área igualmente importantes para a qualidade da educação: o fluxo escolar e as médias de desempenho nas avaliações. É imprescindível notar, nesse ponto, que estudos e análises sobre qualidade educacional raramente combinam rendimento e desempenho, ainda que a complementaridade entre ambos os indicadores seja evidente.

\section{AVALIAÇÃO DA POLÍTICA DE MUNICIPALIZAÇÃO: RESULTADOS E ÍNDICES}

A escolha do IDEB como indicador de qualidade educacional, no trabalho que se apresenta, se baseia na sua abrangência: o Instituto Nacional de Estudos e Pesquisas Educacionais Anísio Teixeira (INEP) oferece os resultados do índice para todas as unidades educativas do país, permitindo uma comparação entre escolas da mesma localidade e de diferentes regiões. Também é possível realizar um estudo comparativo entre escolas estaduais e municipais, além de acompanhar o avanço nas notas desde o lançamento do índice, em 2007, como o trabalho fará. Assim, observam-se os seguintes resultados para as escolas públicas municipais e estaduais entre 2005 a 2017: 


\section{Imagem 1 - Desempenho IDEB: anos iniciais do Ensino Fundamental -}

Escolas Estaduais

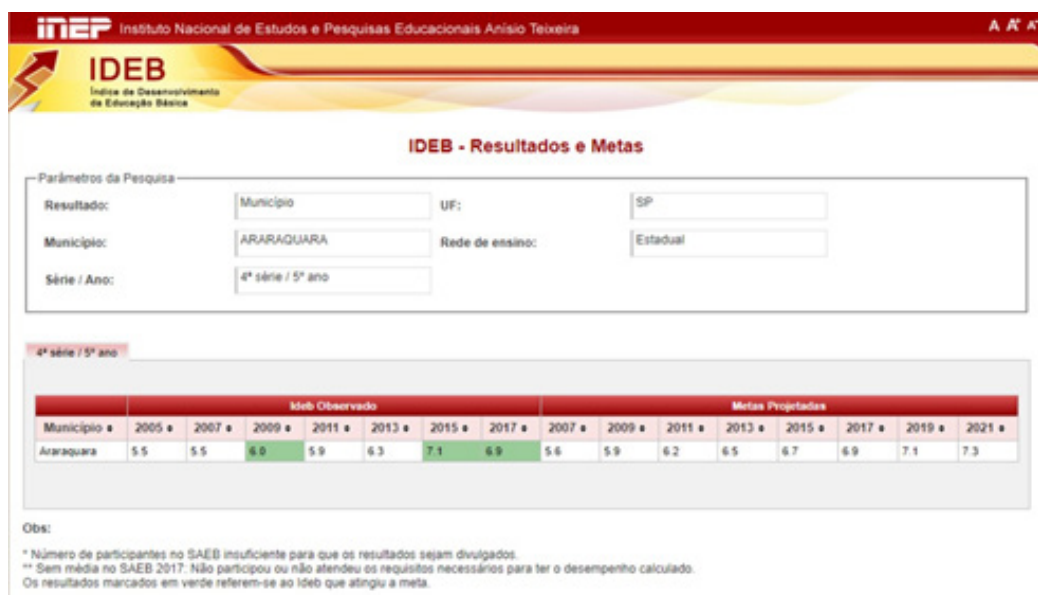

Fonte: INEP (2018)

\section{Imagem 2 - Desempenho IDEB: anos iniciais do Ensino Fundamental - Escolas Municipais}

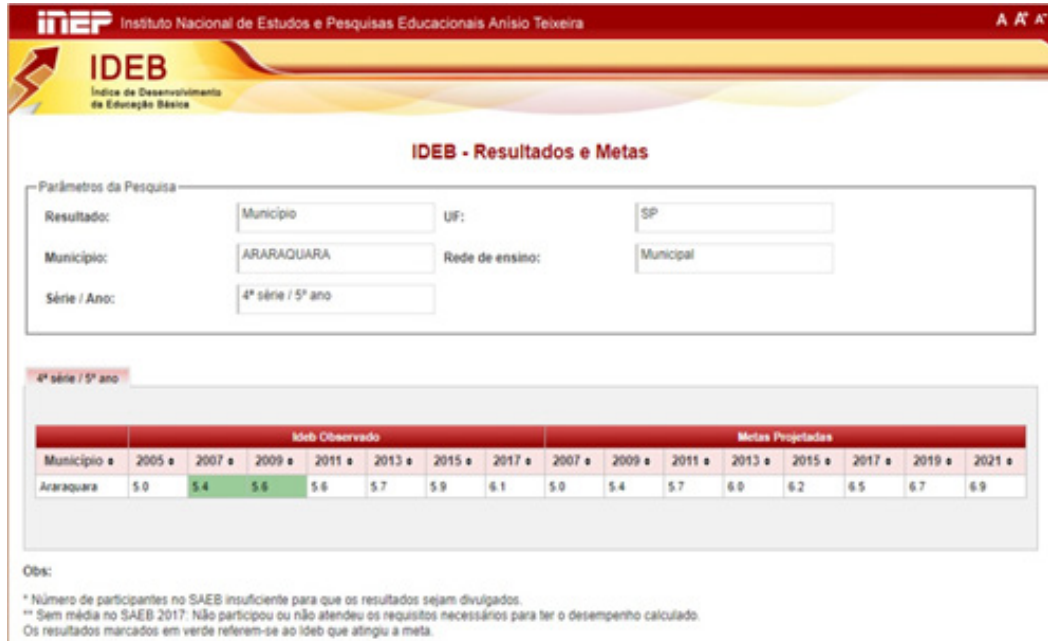

Fonte: INEP (2018)

As notas obtidas por alunos matriculados em escolas geridas pelo município são sempre inferiores às médias obtidas por alunos da rede estadual. Enquanto, em 2005, as escolas municipais partem da nota 5.0, as estaduais 
partem de 5.6, sendo que a trajetória das unidades escolares municipalizadas ou construídas pelo município manteve-se, à exceção de 2007 e 2009, abaixo das metas estabelecidas.

Considerando que tanto o estado quanto o município adotam a política de progressão continuada, ou seja, recomendam às escolas apenas uma reprovação por ciclo, a nota do IDEB seria majoritariamente formada pelo desempenho na Prova Brasil. O instrumento avaliativo não avalia escrita, focando em leitura e interpretação de textos. São medidas capacidades como: localizar informações explícitas em um texto; estabelecer relação de causa/consequência entre partes e elementos do texto; identificar o efeito de sentido decorrente do uso da pontuação e de outras notações; entre outros descritores que buscam mensurar o conhecimento de língua portuguesa dos alunos de quinto ano do EF, além de habilidades matemáticas. Segundo Ghislene e Costa (2019, p. 969), “a ideia de construção de indicadores educacionais não está separada da proposta de haver referências que possam contribuir para um planejamento eficiente no sentido de ajudar a resolver os problemas".

A rede municipal em questão tem sido menos efetiva que a estadual nos indicadores de aprendizagem avaliados pela Prova Brasil, assim como vem se apresentando no restante do país. Ao analisar resultados mais recentes da municipalização, divulgados pelo INEP, a partir do Relatório do $2^{\circ}$ Ciclo de Monitoramento das Metas do Plano Nacional de Educação, em 2018, é possível observar - com base na Avaliação Nacional da Alfabetização (ANA) que foi aplicada aos matriculados no $3^{\circ}$ ano do EF para avaliar a efetividade das ações propostas pelo Pacto Nacional pela Alfabetização na Idade Certa (PNAIC) como tem se dado o processo de alfabetização nas escolas das diferentes redes de ensino brasileiras. No que se refere à capacidade de leitura, o cenário está configurado da seguinte forma: 


\section{Gráfico 2 - Distribuição percentual dos estudantes nos níveis de proficiência em leitura na ANA, por dependência administrativa:$$
\text { Brasil - 2014/2016 }
$$

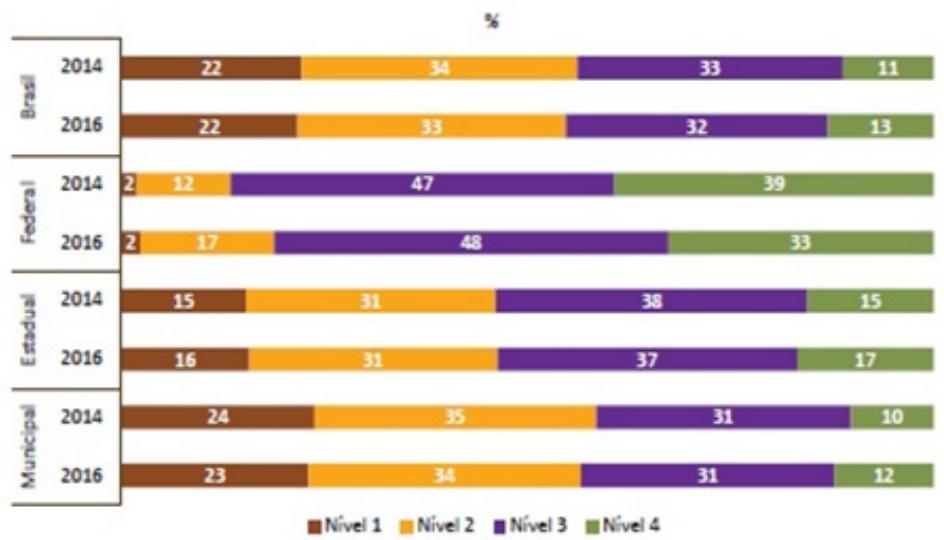

Fonte: Elaborado pela Dired/Inep com base em dados da ANA/Inep (2014/2016)

Assim, os resultados demonstram que escolas de redes municipais apresentam maior quantidade de alunos em níveis iniciais de proficiência para a leitura, em comparação com discentes matriculados em redes estaduais e federal. É importante considerar que o governo federal oferece pequena quantidade de vagas nessa etapa de ensino. Nos dois anos avaliados, a rede municipal apresenta o maior percentual de alunos - 24\% em 2014 e 23\% em 2016 - no nível mais baixo da escala de leitura. Somando os alunos cuja proficiência pertence aos níveis 1 e 2 chega-se a aproximadamente 58\% na rede municipal, $47 \%$ na rede estadual e $17 \%$ na rede federal.

Os dados sobre os índices de proficiência em escrita, para todo o país, podem ser observados no gráfico abaixo: 


\section{Gráfico 3 - Distribuição percentual dos estudantes nos níveis de proficiência em escrita na ANA, por dependência administrativa: Brasil - 2014/2016}

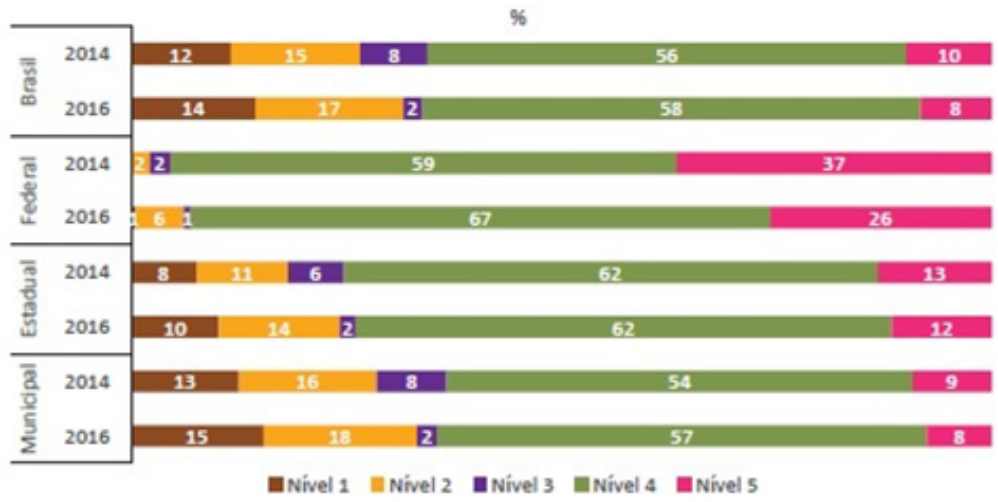

Fonte: Elaborado pela Dired/Inep com base em dados da ANA/Inep (2014/2016)

Novamente, as redes municipais concentram a maior proporção de alunos nos níveis iniciais de proficiência em escrita: cerca de 30\% dos discentes pertenciam aos níveis 1 e 2 da escala, em comparação com $20 \%$ das redes estaduais e $4 \%$ da rede federal, nos anos analisados. Os dados corroboram os resultados apresentados sobre proficiência em leitura, indicando que redes municipais possuem mais dificuldades no processo de alfabetização do que redes estaduais e federal.

Verifica-se, contudo, que mais da metade dos alunos do $3^{\circ}$ ano do EF avaliados na ANA, nos anos 2014 e 2016, encontram-se no nível 4 da escala de proficiência em escrita, em todas as redes de ensino, o que é um indicador positivo para o país.

Outros dados produzidos pelo INEP ajudam a esclarecer o estudo comparativo traçado aqui. Este cenário são os indicadores calculados pelo INEP para todas as escolas brasileiras, e que demonstraremos abaixo com relação a ambas as redes. Os resultados sobre "Complexidade da gestão escolar" apontam aspectos importantes. Antes, porém, faz-se necessário entender os fatores de obtenção do elemento avaliador.

O indicador classifica escolas em níveis de 1 a 6 de acordo com sua complexidade de gestão: níveis elevados indicam maior complexidade. Com base em dados do Censo da Educação Básica, considera-se que a complexidade de gestão está relacionada ao porte da escola; ao número de turnos de funcionamento; à quantidade e complexidade de modalidades/etapas oferecidas. 
Assim, o nível 1 abriga escolas que possuam porte inferior a 50 matrículas, funcionam em único turno, ofertam uma única etapa de ensino e apresentam a EI ou os Anos Iniciais como etapa mais elevada. O 2 se refere a escolas que possuam porte entre 50 e 300 matrículas, funcionam em dois turnos, com oferta de até duas etapas de ensino e apresentam a EI ou os Anos Iniciais como etapa mais elevada. O nível 3 classifica escolas que possuam porte entre 50 e 500 matrículas, funcionam em dois turnos, com oferta de duas ou três etapas de ensino e apresentam os Anos Finais como etapa mais elevada. O 4 identifica escolas que possuam porte entre 150 e 1000 matrículas, funcionam em dois ou três turnos, com oferta de duas ou três etapas de ensino e apresentam o EM, a Educação Profissional ou a EJA como etapa mais elevada. O nível 5 abriga escolas que possuam porte entre 150 e 1000 matrículas, funcionam em três turnos, com oferta de duas ou três etapas de ensino e apresentam a EJA como etapa mais elevada. Finalmente, o 6 inclui escolas que possuam porte superior a 500 matrículas, funcionam em três turnos, com oferta de quatro ou mais etapas de ensino e apresentam a EJA como etapa mais elevada.

A tabela 1 apresenta os dados de complexidade escolar para o município escolhido, de acordo com a natureza da rede de ensino.

\section{Tabela 1 - Complexidade da gestão escolar}

\begin{tabular}{|c|c|c|c|c|c|c|}
\hline Rede / Nível & Nível 1 & Nível 2 & Nível 3 & Nível 4 & Nível 5 & Nível 6 \\
\hline Estadual & 12,8 & 33,3 & 15,4 & 23,1 & 15,4 & 0,0 \\
\hline Municipal & 2,0 & 78,0 & 16,0 & 2,0 & 2,0 & 0,0 \\
\hline
\end{tabular}

Fonte: Censo da Educação Básica 2018/INEP - Adaptado pelos autores

Considerando que o município só oferece educação infantil e ensino fundamental, enquanto o estado possui escolas com EM, faz sentido a concentração de colégios municipais nos níveis iniciais da tabela, visto que a escala é composta pelo número de alunos, turnos de funcionamento e etapas de escolarização oferecidas em cada instituição. O foco da rede municipal, portanto, realmente se encontra nos anos iniciais do EF, nível 2 da tabela.

O segundo indicador, "média de alunos por classe", mostra situação favorável ao município: suas turmas possuem menos discentes, em comparação com as escolas da rede estadual. 
Tabela 2 - Média de alunos por classe

\begin{tabular}{|c|c|c|c|}
\hline Rede / Médias & Total EF & Anos iniciais & Anos finais \\
\hline Estadual & 28,5 & 26,7 & 31,1 \\
\hline Municipal & 23,7 & 23,0 & 25,2 \\
\hline
\end{tabular}

Fonte: Censo da Educação Básica 2018/INEP - Adaptado pelos autores

Enquanto as escolas estaduais possuem uma média de 28 alunos por turma, as municipais contam com 23, diminuindo a taxa de alunos por professor e possibilitando, em tese, maior disponibilidade dos docentes para cada aluno.

O terceiro indicador comparativo, "Regularidade do corpo docente", também necessita de algumas explicações. $\mathrm{O}$ indicador avalia a regularidade do corpo docente nas escolas de EB, por meio da observação da permanência dos professores nas escolas nos últimos cinco anos (2014 a 2018). Para cada docente em cada escola foi atribuída uma pontuação de forma que fosse valorizado: o total de anos em que o docente atuou na escola nos últimos 5 anos, a atuação do docente na escola em anos mais recentes e a atuação em anos consecutivos. O Indicador de Regularidade do Docente (IRD) varia de 0 a 5; quanto mais próximo de 0 , mais irregular é o vínculo do docente com a escola; e quanto mais próximo de 5 , mais regular é esse vínculo. $\mathrm{O}$ indicador de regularidade de cada escola é obtido a partir da média do indicador de regularidade de seus docentes e representa, assim, a regularidade média do corpo docente da escola. As escolas foram classificadas pelas seguintes faixas do indicador de regularidade: Baixa regularidade (IRD médio igual ou menor que 2); Média-baixa (IRD médio maior que 2 até 3); Média-alta (IRD médio maior que 3 até 4); Alta (IRD médio maior que 4 até 5).

A tabela 3 apresenta os dados de regularidade do corpo docente para o município selecionado, de acordo com a natureza da rede de ensino.

Tabela 3 - Regularidade do corpo docente

\begin{tabular}{|c|c|c|c|c|}
\hline Rede / Regularidade & Baixa (0-|2) & Média-baixa (2-|3) & Média-alta (3-|4) & Alta (4-|5) \\
\hline Estadual & 2,7 & 64,9 & 27,0 & 5,4 \\
\hline Municipal & 0,0 & 35,4 & 62,5 & 2,1 \\
\hline
\end{tabular}

Fonte: Censo da Educação Básica 2018/INEP - Adaptado pelos autores

A rede municipal, portanto, possui a maior concentração de docentes na faixa de regularidade média-alta, enquanto a rede estadual possui professores que apresentam constância no nível médio-baixo. Além disso, o município não possui docentes com regularidade baixa. 
Sobre a quantidade de horas/aulas $(\mathrm{h} / \mathrm{a})$ diárias, a rede estadual apresenta uma discreta elevação: enquanto o município oferece $5,1 \mathrm{~h} / \mathrm{a}$, as escolas estaduais ministram 5,3 h/a, como pode ser observado na Tabela 4.

Tabela 4 - Quantidade de horas/aula diárias (HAd)

\begin{tabular}{|c|c|c|c|}
\hline Rede / HAd & Total EF & Anos iniciais & Anos finais \\
\hline Estadual & 5,3 & 5,1 & 5,5 \\
\hline Municipal & 5,1 & 5,1 & 5,2 \\
\hline
\end{tabular}

Fonte: Censo da Educação Básica 2018/INEP - Adaptado pelos autores

A diferença se acentua especialmente nos anos finais do EF (5,2 h/a no município versus $5,5 \mathrm{~h} /$ a no estado). Nos anos iniciais, tanto o município quanto o estado dispõem da mesma média de horas/aula.

O "Indicador de esforço docente", que classifica os professores de acordo com o número de escolas, turnos e etapas em que atuam, assim como os alunos que possuem, demonstra que o município conta com mais docentes concentrados em uma única escola, em comparação com a rede estadual. Para entender melhor, o Indicador de esforço docente estabelece uma classificação do docente em níveis de 1 a 6 de acordo com o esforço empreendido no exercício da profissão, em que níveis elevados indicam maior esforço.

A partir dos dados disponíveis no Censo da Educação Básica, considerase que o esforço docente está relacionado às seguintes características da docência: número de escolas em que atua; número de turnos de trabalho; número de alunos atendidos; e número de etapas nas quais leciona. O nível 1 indica que o docente tem até 25 alunos e atua em um único turno, escola e etapa. O 2 identifica o docente que tem entre 25 e 150 alunos e atua em um único turno, escola e etapa. O nível 3 aponta o docente que tem entre 25 e 300 alunos e atua em um ou dois turnos em uma única escola e etapa. O 4 reúne docentes que têm entre 50 e 400 alunos e atua em dois turnos, em uma ou duas escolas e em duas etapas. O nível 5 indica que o docente tem mais de 300 alunos e atua nos três turnos, em duas ou três escolas e em duas etapas ou três etapas. Finalmente, o 6 identifica docentes que têm mais de 400 alunos e atua nos três turnos, em duas ou três escolas e em duas etapas ou três etapas. 


\section{Tabela 5 - Indicador de Esforço Docente}

\begin{tabular}{|c|c|c|c|c|c|c|}
\hline Rede / Nível & Nível 1 & Nível 2 & Nível 3 & Nível 4 & Nível 5 & Nível 6 \\
\hline Estadual & 8,0 & 23,0 & 15,8 & 36,4 & 10,5 & 6,3 \\
\hline Municipal & 33,0 & 21,0 & 14,8 & 21,0 & 6,7 & 3,5 \\
\hline
\end{tabular}

Fonte: Censo da Educação Básica 2018/INEP - Adaptado pelos autores

Este dado, aliado à informação sobre a regularidade do corpo docente, indica que as escolas municipais possuem professores mais estáveis, de maneira geral, atuantes em uma mesma escola e em um único turno, em sua maioria.

O indicador "Distorção idade-série" é fundamental por demonstrar possíveis dificuldades de aprendizagem que perpassam toda a vida escolar dos alunos, impedindo-os de prosseguir os estudos em suas turmas correspondentes. Os dados podem ser encontrados na Tabela 6 .

\section{Tabela 6 - Taxa de distorção idade-série}

\begin{tabular}{|c|c|c|c|}
\hline Rede / Distorção & Total EF & Anos iniciais & Anos finais \\
\hline Estadual & 5,1 & 1,8 & 8,1 \\
\hline Municipal & 7,7 & 4,4 & 14,4 \\
\hline
\end{tabular}

Fonte: Censo da Educação Básica 2018/INEP - Adaptado pelos autores

Desde os anos iniciais, o município possui uma taxa de distorção maior. Isso pode significar que alunos são matriculados mais tardiamente nas escolas municipais, mas na medida em que a taxa aumenta mais em anos finais, a explicação possível está no fluxo: mais discentes são retidos e não conseguem acompanhar suas turmas de origem.

Outro indicador importante é o Índice de Nível Socioeconômico (INSE) $)^{7}$, que reúne as escolas públicas localizadas no município escolhido tanto estaduais quanto municipais - nos níveis 3, 4 e 5, com a grande maioria pertencente ao grupo 4. A escala vai de 1 a 8 , com o intuito de determinar o nível socioeconômico dos alunos com base nos bens possuídos pela família. O nível 4 agrega unidades familiares que possuem em sua residência bens elementares: dois ou três quartos para dormir, um banheiro, uma geladeira, três ou mais telefones celulares e um ou dois televisores; bens complementares: máquina de lavar roupas, micro-ondas, computador, um telefone fixo e um carro; bens suplementares: freezer; renda familiar mensal: entre 1,5 e 3 salários mínimos; e pais ou responsáveis que completaram o ensino médio ou a faculdade. $\mathrm{O}$ município mantém um padrão de 
renda média para os padrões nacionais, e todas as escolas do município acabam se enquadrando nas mesmas categorias, que não refletem as particularidades de cada bairro.

\section{CONSIDERAÇÕES FINAIS}

Como análise geral, é factível deduzir que a rede municipal possui mais inputs positivos - escolas com níveis de gestão menos complexos, professores mais regulares e menos sobrecarregados, menor média de alunos por sala e carga horária similar ao estado nos anos iniciais do EF - e, no entanto, apresenta resultados inferiores aos obtidos pela rede estadual: maior taxa de distorção idade-série e menor desempenho no IDEB.

Aqui podemos mencionar que as escolas municipalizadas ou construídas com recursos municipais estão localizadas em áreas periféricas, de maior vulnerabilidade socioeconômica, em comparação com a alocação das escolas pertencentes à rede estadual, que compõem um corredor central. Vale lembrar que o INSE não reflete tais particularidades, já que tanto as residências das regiões centrais quanto as da periferia, em Araraquara, apresentam características semelhantes no que se refere ao número de quartos e bens complementares e suplementares.

Dessa maneira, os discentes matriculados na rede municipal - e suas famílias - residem em localidades afastadas do centro urbano, portanto, com menos acesso aos equipamentos locais disponíveis em termos de saúde, habitação, lazer. Nesses locais, o papel da escola é ampliado: vista, muitas vezes, como a única referência de acolhimento, acaba sendo sobrecarregada de demandas que fogem à sua alçada.

$\mathrm{Na}$ literatura da área, encontramos trabalhos que corroboram essa tendência. Em balanço recente das pesquisas que buscam compreender as conexões entre vulnerabilidade social do território e desigualdade escolar no país, Vanda Mendes Ribeiro e Cláudia Lemos Vóvio concluíram o seguinte:

\footnotetext{
Pode-se dizer, portanto, que os resultados das pesquisas apontam para a existência de vínculos entre desigualdades socioespaciais (indicadas pela interface entre sobreposição de desigualdades e segregação social no território), desigualdades sociais (indicadas pelos níveis de recursos socioeconômicos e culturais dos alunos e famílias) e desigualdade escolar (vista pelos resultados educacionais, expectativa sobre os alunos, formação e experiência dos professores e pela infraestrutura das escolas). (RIBEIRO; VOVIO, 2017, p. 84)
} 
Diante de tais situações, é imprescindível a atuação do poder público local, por meio de outras instituições, de maneira que torne possível a retomada da função da escola que é transmitir os conhecimentos acumulados pela ciência para as novas gerações.

Além disso, importa salientar que, ao contrário do estado de São Paulo, que já oferta educação em nível fundamental há muitos anos, o município de Araraquara não possuía experiência anterior de gestão nesta etapa de ensino. Nesse sentido, é consenso na literatura que dotar a escola de autonomia é vantajoso, visto que possibilita a seus atores a realização de projetos próprios. No entanto, problemas gerados pela falta de capacitação do funcionalismo de pequenos municípios, assim como a verba disponível totalmente comprometida com a folha de pagamento tornam a pretensa autonomia local mero detalhe, em contraposição ao esperado nas análises realizadas no início do processo de municipalização, como podemos observar na afirmação abaixo:

Contrariamente ao modelo anterior, a escola terá que ser vista como uma
organização construída socialmente; portanto, com ênfase no processo de
interação social que aí se desenvolve antes que nos aspectos formais que a
caracterizam, impondo limites rígidos e intransponíveis. Ainda que constitua
uma unidade dentro de um sistema mais amplo, cada escola terá de ser vista
em sua identidade própria, e para tanto ela necessita de autonomia. (ALONSO,
2003, p. 117)

Para que tal objetivo volte a ser visto como um ideal a ser alcançado, cumpre fortalecer a atuação dos conselhos de acompanhamento e fiscalização dos recursos do FUNDEB, democratizar a participação da comunidade no processo de elaboração do orçamento educacional e promover a transparência dos gastos na área, engajando os pais nas decisões sobre o funcionamento da escola.

\section{REFERÊNCIAS}

ALONSO, M. Autonomia da Escola e Participação. In: VIEIRA, A. T.; ALMEIDA, M. E. B. de; ALONSO, M. Gestão educacional e tecnologia. São Paulo: Avercamp, 2003

ARARAQUARA. Câmara Municipal. Lei Municipal n. 3861, de 10 de julho de 1991. Dispõe sobre o Estatuto do Magistério Público do Município de Araraquara e dá outras providências. Disponível em: https://leismunicipais.com. br/a/sp/a/araraquara/lei-ordinaria/1991/386/3861/lei-ordinaria-n-3861-1991dispoe-sobre-o-estatuto-do-magisterio-publico-do-municipio-de-araraquara-eda-outras-providencias. Acesso em: 15 jun. 2019. 
ARARAQUARA. Câmara Municipal. Lei Municipal n. 4938, de 13 de novembro de 1997. Dispõe sobre a instituição do sistema municipal de ensino e dá outras providências. Disponível em: https://c-mara-municipal-da-araraquara.jusbrasil. com.br/legislacao/294306/lei-4938-97. Acesso em: 11 set. 2020.

AZEVEDO, F. et al. Manifestos dos pioneiros da Educação Nova (1932) e dos educadores (1959). Recife: Fundação Joaquim Nabuco, Editora Massangana, 2010. Disponível em: http://www.dominiopublico.gov.br/download/texto/ me4707.pdf. Acesso em: 30 maio 2019.

BRASIL. Constituição (1988). Constituição da República Federativa do Brasil. Brasília, DF: Senado Federal: Centro Gráfico, 1988.

GHISLENI, A. C.; COSTA, D. M. A avaliação revisitada: novos espaços do político e do pedagógico na gestão educacional. Revista Ibero-Americana de Estudos em Educação, Araraquara, v. 14, n. 3, p. 956-972, jul./set. 2019. e-ISSN: 19825587. Disponível em: https://periodicos.fclar.unesp.br/iberoamericana/article/ view/11830/8144. Acesso em: 24 jun. 2020. DOI: 10.21723/riaee.v14i3.11830

IBEIRO, V. M.; VOVIO, C. L. Desigualdade escolar e vulnerabilidade social no território. Educ. rev., Curitiba, n. spe. 2, p. 71-87, set., 2017. Disponível em: http://www.scielo.br/scielo.php?script=sci_arttext\&pid=S010440602017000600071\&lng=en\&nrm=iso. Acesso em: 15 abr. 2019

INEP. Instituto Nacional de Estudos e Pesquisas Educacionais Anísio Teixeira. Censo da Educação Básica 2018. Brasília, DF, 2018.

INEP. Instituto Nacional de Estudos e Pesquisas Educacionais Anísio Teixeira. IDEB - Resultados e Metas. 2018. Brasília, DF, 2019. Disponível em: http:/ / ideb.inep.gov.br/. Acesso em: 15 maio 2019

INEP. Instituto Nacional de Estudos e Pesquisas Educacionais Anísio Teixeira. Matrizes e Escalas: Prova Brasil e ANA. Brasília, DF. Página atualizada em: 29 out. 2019. Disponível em: http://portal.inep.gov.br/web/guest/educacaobasica/saeb/matrizes-e-escalas. Acesso em: 12 set. 2019.

INEP. Instituto Nacional de Estudos e Pesquisas Educacionais Anísio Teixeira. Relatório do $2^{\circ}$ Ciclo de Monitoramento das Metas do Plano Nacional de Educação - 2018. Brasília, DF: Inep, 2018. 460 p. 
MARTINS, A. M. (Org.). O processo de municipalização no estado de São Paulo. São Paulo: Fundação Carlos Chagas, 2002. Relatório de Pesquisa.

OLIVEIRA, R. de. Comportamento do IDEB nos municípios paulistas da região de Barretos e região Central: algumas discussões para responsabilização e comprometimento. 2015. 81 f. Dissertação (Mestrado em Educação Escolar) - Faculdade de Ciências e Letras. UNESP, Araraquara, 2015. Disponível em: http://hdl.handle.net/11449/123865. Acesso em: maio 2019.

SIOPE. Sistema de Informações sobre Orçamentos Públicos em Educação. 2018. Disponível em: https://www.fnde.gov.br/siope/ indicadoresFinanceirosEEducacionais.do. Acesso em: 23 maio 2019.

SOUZA, A. R. de. As relações entre os resultados da avaliação e os modelos de gestão escolar. InterMeio: revista do Programa de Pós-Graduação em Educação, Campo Grande, MS, v. 13, n. 25, 2017. Disponível em: http://seer. ufms.br/index.php/intm/article/view/2547/1770. Acesso em: 20 out. 2019.

TAVEIRA, A. do V. Descentralização e desconcentração na atividade estatal. Revista Paradigma, Ribeirão Preto, n. 18, p. 236-247, 2009.

TEIXEIRA, A. A municipalização do ensino primário. Revista Brasileira de Estudos Pedagógicos, v. XXVII, n. 66, abr./jun. 1957.

THIESEN, J. da S. Currículos da Educação Básica Brasileira: convergências com o discurso educacional global em contextos de internacionalização. Revista Ibero-Americana de Estudos em Educação, Araraquara, v. 14, n. 2, p. 420 436, abr./jun. 2019. e-ISSN: 1982-5587. Disponível em: https://periodicos.fclar. unesp.br/iberoamericana/article/view/11306/8028. Acesso em: 24 jun. 2020. DOI: $10.21723 /$ riaee.v14i2.11306

\section{Thaís Conte Vargas}

Doutoranda em Educação Escolar - Faculdade de Ciências e Letras (FCLAr). E-mail: thaiscontev@hotmail.com 


\section{José Luís Bizelli}

Livre docente. Programa de Pós-Graduação em Educação Escolar - Faculdade de Ciências e Letras (FCLAr). Pesquisador Bolsista de Produtividade em Pesquisa 2 -CNPq. E-mail: jose.bizelli@unesp.br

\section{José Anderson Santos Cruz}

Doutorando em Educação Escolar - Faculdade de Ciências e Letras (FCLAr). Orientador Colaborador ESALQ/PECEGE. Editor Adjunto de Periódicos e Assessor Técnico em Gestão de Periódicos Científicos. Editor Editora IberoAmericana de Estudos em Educação. Bolsista CAPES. E-mail: anderson.cruz@ unesp.br 